\title{
Time poverty: Obstacle to women's human rights, health and sustainable development
}

\section{Elizabeth Hyde $^{1}$, Margaret E Greene ${ }^{2}$, Gary L Darmstadt ${ }^{3}$}

\author{
${ }^{1}$ Stanford University School of Medicine, Stanford, California, USA \\ ${ }^{2}$ GreeneWorks, Washington, D.C., USA \\ ${ }^{3}$ Department of Pediatrics, Stanford University School of Medicine, Stanford, California, USA
}

Inequitable gender-based allocation of unpaid work leaves women with relatively little discretionary time, endangers women's health and the health of their children, limits women's economic opportunities, curtails women's voice and leadership, and is a manifestation of systemic oppression of women via gender inequality and restrictive gender norms.

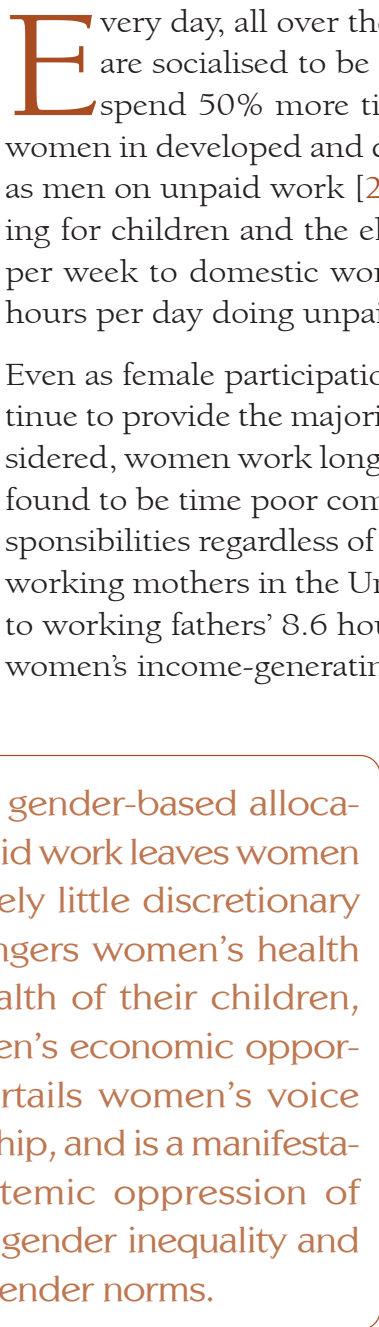
der differences in housework-related indicators accounted for $27 \%-28 \%$ of the gender earnings gap [8].

This inequitable gender-based allocation of unpaid domestic work, representing "double-duty" for women who enter the workforce, often leaves women with little or no discretionary time. This is known as time poverty. Time poverty has important repercussions for women's economic opportunities and health, and is a manifestation of the systemic oppression of women via gender inequality and restrictive gender norms which dictate normative expectations for what it means to be male or female in a given society and the roles, responsibilities, and privileges that are allocated to a person based on those norms. Restrictive gender norms limit women's access to paid employment, resources, and control over how resources (including their own time) are used. Time poverty is a human rights issue that must be addressed in order to fulfill the Sustainable Development Goals 
Improving women's control over their time benefits their own health and economic opportunities, as well as the health and economic development of their families, communities, nations, and the world. Ultimately, women's time poverty must be addressed as essential to achieving the Sustainable Development Goals, a global moral imperative and a fundamental human right.

and empower women and girls everywhere to achieve their full human potential, with lasting benefits for their families, communities and nations.

\section{HEALTH CONSEQUENCES OF TIME POVERTY}

Time poverty harms women's health through numerous pathways (Table 1). Domestic responsibilities can leave little time for women to seek medical care, promoting self-neglect. One study in the United States found that almost one-quarter of American women reported delaying or not seeking health care due to insufficient time [9], and another found that being female and having a child in the household to care for were both predictors of delaying HIV care [10]. Among pregnant South African women, daily chores such as fetching water and fieldwork have been shown to decrease use of prenatal care [11].

Without money of their own, women's inability to afford health care services or medicines may be further exacerbated. In a study of rural Bangladeshi women, not being involved in income-generating activities was associated with increased delay in seeking emergency obstetric care [12].

Time poverty can also result in poorer food choices and less exercise, and can impose significant mental stress on women and girls. One study in the United States found that time-poor individuals are less likely to walk or cycle for exercise, though they are also less likely to purchase fast food [13].

\section{ECONOMIC CONSEQUENCES OF TIME POVERTY}

Time poverty also prevents women from fully engaging in the formal/monetised economy, limited economic productivity and growth in several ways (Table 1). Lack of time due to domestic responsibilities impedes women from completing school, obtaining paid work, and working as many hours for pay as men, funneling women into lower-paying jobs. In 2018, women in the United States were five times as likely as men to work in occupations with poverty-level wages across all occupations [14].

This results in a significant loss of income for women and national economies. The World Bank estimated in 2018 that among people aged 25-34 in peak productive and reproductive years, 122 women were living in poverty for every 100 men [15].

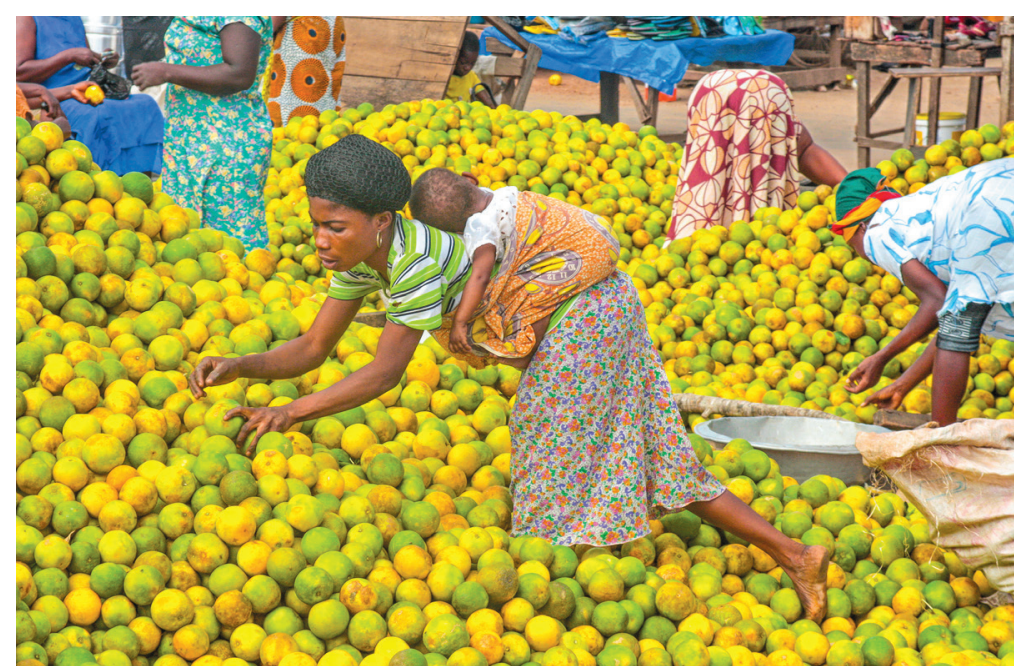

Photo: iStock Getty Images.
Though unpaid care is critical for the functioning of society and the global economy, it is invisible by most metrics of productivity. Though women spend a large fraction of their time working, they are credited with producing only $37 \%$ of global GDP [16]. One study in Guatemala estimated that the value of household and caregiving work totaled 30\% of the nation's GDP in 2000 [4], yet it remains completely unrecognised in economic statistics.

Increasing the share of income earned by women has been shown to shift spending priorities in favor of future generations. Evidence from diverse settings (eg, Brazil, Bangladesh, Côte d'Ivoire, Mexico, South Africa, United Kingdom) indicates that increasing women's control 
Table 1. The impact of time poverty on women's health and economic prospects*

HEALIH

Time poverty promotes

self-neglect
- Limited discretionary time due to a large caregiving burden can prevent women from seeking their own medical care [S1]. In 2017, 24\% of American women reported delaying or not obtaining health care because they could not find time, and $14 \%$ cited trouble finding child care [S2].

- In a study of HIV patients in the United States, being female and having a child in the household were both predictors of delaying HIV care due to caregiving [S3]

- Among pregnant South African women, daily chores such as fetching water and fieldwork have been shown to decrease use of prenatal care [S4].

- Among pregnant women in Benin, educational attainment and being employed - which require sufficient time - were associated with increased utilization of maternal health care [S5].

Time poverty prevents wom- - In a study of rural Bangladeshi women, a lack of income-generating activity was associated with increased delay in seeking en from earning money, emergency obstetric care [S6].

which can limit their ability to pay for health care

Time poverty curtails wom- - A study of Aboriginal women in Manitoba found that caregiving responsibilities were a significant barrier to academic progen's educational opportunities ress [S7]. and capabilities for enagaging with health systems

Time poverty results in poorer - Time poverty promotes unhealthy eating habits and decreased exercise [8]. Conversely, in a review of the impact of leisure food choices, less exercise, time on health, leisure time was associated with identity formation and affirmation, improved coping during times of stress, and more stress and positive effects on work and relationships [S9].

- A 2017 study found that American fathers engaged in leisure activities 47\% and 35\% of the time during which mothers did childcare and housework, respectively [S10].

- Caregiving can also be mentally and physically taxing. Among American women caring for adult relatives, mental health is worse than national norms [S11]. Grandmothers who take significant caregiving roles for their grandchildren have been to shown to suffer increased stress compared to non-caregiving counterparts [S1].

\section{Economic prospects:}

Unpaid responsibilities limit • Worldwide, three-quarters of men and one half of women are part of the paid labor force [S12]. In 2015, <30\% of women women's engagement in the workforce

in Northern Africa, Western Asia, and Southern Asia worked for pay [S12].

- Unpaid caregiving duties are a significant barrier to employment, particularly for mothers. In 2013, American mothers were almost three times as likely as fathers to report quitting their jobs at some point for family reasons [S13].

- Male-dominated occupations often require long hours with little flexibility, which does not accommodate caregiving responsibilities [S14]. Mothers in these fields were 52\% more likely to quit than other women if they worked $\geq 50$ hours per week.

- In the United States, 69\% of unpaid caregivers to elderly adults are women [S15]. Daughters and daughters-in-law are more likely than other caregivers to reduce their work hours to care for ageing parents [S16]

Women in the paid workforce • Female-dominated professions such as teaching, administrative services, and food production tend to pay less than male-domare funneled into lower-paid occupations with fewer protections

inated jobs, even when they require the same skill level [S17]. They reflect women's lower educational attainment, limited mobility, discrimination by employers, normative choices, and the necessity of part-time work to accommodate domestic work [S18]. The same trends are seen in the health sector, where "women care and men cure" [S19].

- Women tend to occupy lower levels and be paid less than men working in the same industries. For example, in the Canadian food service industry in $2015,60 \%$ of chefs were male, while $72 \%$ of kitchen helpers were female [S20]. Women are under-represented in high-paid sectors like technical and business services [S18,S21,S22].

- Lower-paid roles tend to offer poorer working conditions and be excluded from social protection programs designed to reduce social and economic vulnerability [S22,S23,S24].

- In the Middle East, legal coverage for employment injury is 18 percentage points lower for women than overall coverage rates [S25].

Gender segregation in the - The decline in occupational segregation by gender in the United States has significantly slowed in recent decades, regardless workplace persists due to of the education level required for the work [S26]. In 2018, only 7.2\% of American women worked full-time in male-domovert and subtle harassment inated ( $275 \%$ male) fields [S27].

and discrimination

- Male-dominated occupations are often hostile environments for women and have the highest rates of gender-based harassment $[$ S28,S29]. Women majoring in majority-male fields face significantly more gender harassment than women in other majors [S30].

- Discrimination on hiring and promoting men over women is pervasive in finance and STEM fields, limiting women's advancement and reinforcing gender-based occupational segregation [S29,S31,S32]

- $37 \%$ of women who work mostly with men report that they have been treated as if they were incompetent because of their gender, compared to $18 \%$ of women in gender-balanced workplaces [S29].

Women are paid less than • Jobs with more women pay less than those with fewer, even when controlling for education level and skills [S33]. In most men for similar work countries, across all sectors and occupations, women working full-time earn $70 \%-90 \%$ of what men earn doing the same work [S12].

- Women earn less than men in all male-dominated occupations and 18 of the 20 most common occupations for women [S27].

- Devaluation of women's work has been shown to be a primary driver of the gender wage gap [S33]. The overall pay rate of male-dominated occupations in the United States declined as large numbers of women entered the fields between 1950 and 2000 [S33].

*References are presented in Table S1 in the Online Supplementary Document. 
over resources translates to greater investment in children's nutrition, health, and education. A multi-country study revealed that increasing female representation in parliaments results in greater spending on education as a percentage of GDP [17]. In one analysis of 76 studies conducted in low and middle income countries, women's decision-making power and education were found to correlate strongly with improved outcomes across multiple sectors, demonstrating that expanding women's agency broadly improves health and development for women, their families, and their communities [18].

\section{CONCLUSION}

Time poverty endangers women's health and the health of their children, sharply limits women's economic opportunities, and curtails women's voice and leadership and limits women's opportunities to exert influence on their societies through their leadership in work and in public life. Time poverty is also a symptom of a more fundamental problem: gendered social norms that give men power over women, assign lesser value to women and their contributions, and maintain the current inequitable distribution of power and wealth between men and women.

Some strides have been made in recent years in recognising the issue and working toward remedies. Efforts have been made to formalise the definition of time poverty], increase men's involvement in unpaid caregiving and housework, implement novel programmes such as financial incentives for low-income women to seek health care when needed, and develop time-saving technologies like stoves that require less gathering of firewood to function.

Improving women's control over their own time benefits their own health and economic opportunities, as well as the health and economic development of their families, communities, nations, and the world. Ultimately, however, women's time poverty must be addressed as a global moral imperative and a fundamental human right.

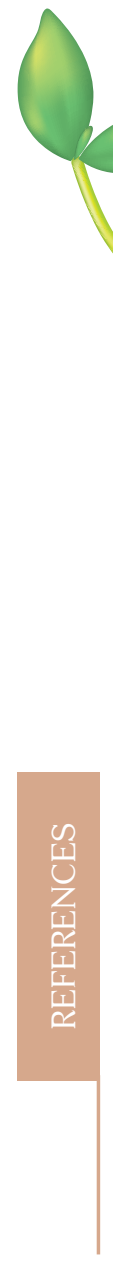

Acknowledgements: We thank Sarah Henry in the Department of Pediatrics at the Stanford University School of Medicine for her intellectual contributions to early versions of the manuscript.

Authorship contributions: EH conceptualized the study, conducted the desk research, drafted the initial manuscript, and reviewed and revised the manuscript. GLD conceptualized the study and reviewed and revised the manuscript. MEG provided intellectual input, contributed to drafting the manuscript, and reviewed and revised the manuscript. All authors approved the final manuscript as submitted and agree to be accountable for all aspects of the work.

Funding: This work was supported in part by the Bill \& Melinda Gates Foundation through a grant to the senior author at Stanford University. The funders had no role in the preparation of this article. The views expressed are those of the authors and are not necessarily those of the Bill \& Melinda Gates Foundation.

Competing interests: The authors completed the ICMJE Unified Competing Interest form (available upon request from the corresponding author), and declare no conflicts of interest.

\section{Additional material}

Online Supplementary Document

1 UNICEF. Harnessing the Power of Data for Girls: Taking Stock and Looking Ahead to 2030. New York, NY: UNICEF; 2016.

2 Division UNS. The World's Women 2015, Chapter 4: Work.; 2015.

3 Bardasi E, Wodon Q. Working Long Hours and Having No Choice: Time Poverty in Guinea. Fem Econ. 2010;16:45-78. doi:10.1080/13545701.2010.508574

4 Gammage S. Time Pressed and Time Poor: Unpaid Household Work in Guatemala. Fem Econ. 2010;16:79. doi:10.108 O/13545701.2010.498571

5 us Saqib N, Arif GM. Time Poverty, Work Status and Gender: The Case of Pakistan. Pakistan Institute of Development Economics; 2012. Available: https://pdfs.semanticscholar.org/b529/9aff90ed9c058f9ef32e617e384376c77d25.pdf?_ ga=2.94353053.1870627998.1576765739-1405398481.1576283957. Accessed: 6 June 2020.

6 Parker K. Women More than Men Adjust Their Careers for Family Life. Pew Research Center; 2015. Available: https:// www.pewresearch.org/fact-tank/2015/10/01/women-more-than-men-adjust-their-careers-for-family-life/. Accessed: 6 June 2020. 
7 Arora D. Gender Differences in Time-Poverty in Rural Mozambique. Rev Soc Econ. 2015;73:196. doi:10.1080/003467 64.2015 .1035909

8 Qi L, Dong X-Y. Housework Burdens, Quality of Market Work Time, and Men's and Women's Earnings in China. University of Winnipeg Department of Economics; 2013.

9 Ranji U, Rosenzweig C, Gomez I, Salganicoff A. 2017 Kaiser Women's Health Survey. The Henry J. Kaiser Foundation; 2018.

10 Stein MD, Crystal S, Cunningham WE, et al. Delays in seeking HIV care due to competing caregiver responsibilities. Am J Public Health. 2000;90:1138-40. Medline:10897195 doi:10.2105/AJPH.90.7.1138

11 McCray TM. An issue of culture: the effects of daily activities on prenatal care utilization patterns in rural South Africa. Soc Sci Med. 2004;59:1843-55. Medline:15312919 doi:10.1016/j.socscimed.2004.02.033

12 Nahar S, Banu M, Nasreen H. Women-focused development intervention reduces delays in accessing emergency obstetric care in urban slums in Bangladesh: a cross-sectional study. BMC Pregnancy Childbirth. 2011;11:11. Medline:21276263 doi:10.1186/1471-2393-11-11

13 Kalenkoski C, Hamrick K. How Does Time Poverty Affect Behavior? A Look at Eating and Physical Activity. Appl Econ Perspect Policy. 2013;35:89-105. doi:10.1093/aepp/pps034

14 Cha Y. Overwork and the Persistence of Gender Segregation in Occupations. Gend Soc. 2013;27:158-84. doi:10.1177/0891243212470510

15 Munoz Boudet AM, Buitrago P, De La Briere B, et al. Gender Differences in Poverty and Household Composition through the Life-Cycle. Washington DC: World Bank Group; 2018.

16 Woetzel J, Madgavkar A, Ellingrud K, et al. The Power of Parity. McKinsey Glob Inst Insights Publ. 2015;(September).

17 Chen L-J. Female policymakers and educational expenditures: cross-country evidence. Eur J Comp Econ. $2008 ; 1$. doi:10.2139/ssrn. 1117552

18 Taukobong HFG, Kincaid MM, Levy JK, Bloom SS, Platt JL, Henry SK, et al. Does addressing gender inequalities and empowering women and girls improve health and development programme outcomes? Health Policy Plan. 2016;31:1492514. Medline:27371549 doi:10.1093/heapol/czw074

Correspondence to:

Gary L. Darmstadt, MD,

Department of Pediatrics

Stanford University School of Medicine

1701 Page Mill Road

Palo Alto, CA, 94304

USA

gdarmsta@stanford.edu 